\title{
EDITORIAL \\ Machine learning and artificial intelligence applied to the diagnosis and management of Cushing disease
}

\author{
Edward R. Laws Jr., MD, and Michael P. Catalino, MD, MSc \\ Department of Neurological Surgery, Brigham and Women's Hospital, Harvard Medical School, Boston, Massachusetts
}

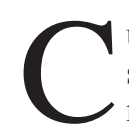
USHING disease is defined as hypercortisolism resulting from a pituitary tumor that secretes abnormal and excessive amounts of adrenocorticotropic hormone (ACTH). This definition is quite straightforward; however, the actual diagnosis of Cushing disease can be elusive, confusing, and aggravating for both patients and caregivers. ${ }^{3}$ The source of these diagnostic difficulties lies in the plethora of symptoms, laboratory tests, and imaging studies that are currently utilized in attempts to establish an accurate differential diagnosis. With so many factors that must be taken into account, it would seem that these diagnostic and management efforts would be prime candidates for assessment using artificial intelligence or machine learning platforms.

Currently, the diagnosis and management of Cushing disease can be extraordinarily challenging, clouding the indications for surgery and negatively impacting the outcomes of treatment even after presumed effective therapy. ${ }^{6}$ Accurate diagnosis and long-term follow-up are critical to fully understanding the outcomes from treatment of this highly morbid disease. The entire patient assessment process hinges on the demonstration and localization of an ACTH-dependent pituitary source of pathologically elevated serum cortisol. Patients may have typical presentations, but often patient presentations are atypical and may exhibit numerous features that overlap with metabolicand obesity-related endocrine syndromes. ${ }^{11}$ More than 20 characteristic signs and symptoms have been reported by patients with Cushing disease. These and other features combine to create sensitive but sometimes confusing diagnostic criteria. The diagnosis is further compromised by the fact that many patients suffer from neurocognitive derangements, including mood disorders, psychological instability, and impaired verbal learning and memory. ${ }^{1,2,10}$ No combination of these clinical features has yet proven specific enough for definitive diagnosis, and each case presents a unique challenge at initial and subsequent presentations.
The article by Zoli and associates describes an attempt to use machine learning in an exhaustive study of 151 consecutive patients evaluated for the diagnosis and management of Cushing disease. ${ }^{12}$ An ideal machine learning analysis for this type of investigation would include weighted estimates of as many characteristics of patients with Cushing disease as possible, including clinical signs and symptoms, a variety of separate laboratory tests, ${ }^{5}$ details of neuroimaging and nuclear imaging (PET) studies, and results of dynamic testing, such as inferior petrosal sinus sampling (IPSS) (Table 1). ${ }^{6}$ The machine learning process then correlates these elements with outcome results associated with an optimal treatment recommendation or a variety of graded treatment strategies. Once Cushing disease of pituitary origin is diagnosed, transsphenoidal surgery for resection of a presumed pituitary adenoma is usually considered the first-line therapy.,7,9

The ambitious study by Zoli and associates is an intriguing first step. Although the number of factors analyzed was limited, the authors were able to isolate some factors that were in fact associated with their admirable postsurgical remission rate $(88 \%)$. Overall, Zoli et al. selected endpoints to be examined that consisted of grosstumor removal, postsurgical remission, and "long-term" control of disease. The reported results are quite satisfactory and are a testament to the careful analysis and followup provided by the authors.

As the authors noted in their discussion of the results, careful clinical interpretation of the major factors resulting in successful treatment, disease recurrence, or treatment failure is not possible without studies based on an increased patient sample size. One would also presume that more comprehensive evidence from clinical, laboratory, and imaging settings is necessary to fully assess the benefits of a machine learning approach to the thorny questions relating to diagnosis and optimal management in patients with Cushing disease. One can consider at least 29 symptoms and signs variably associated with Cush- 
TABLE 1. Diagnostic and prognostic variables to be considered in the complex management of Cushing disease and biochemical outcome prediction after surgery

\begin{tabular}{|c|c|c|c|c|}
\hline Clinical Finding & Laboratory Test & Imaging & Operative Factor & Tumor Factor \\
\hline Obesity/weight gain & Fasting AM cortisol & MRI, pituitary & Tumor found & Pathology \\
\hline Diabetes mellitus & Fasting AM ACTH & Knosp score* & Tumor removed & $\mathrm{IHC} / \mathrm{TF}$ \\
\hline Hypertension & 24-hr UFC ×2 & CT chest/abd/pelvis & Extent of resection & MIB-1† \\
\hline Moon facies & LNSC $\times 2$ & Plain radiographs & CS ext/invasion & Crooke's changes \\
\hline Facial plethora & Serum K, Ca & FDG-PET & Dural invasion & \\
\hline Dysmenorrhea & DHEAS & Octreotide & Pseudocapsule CSF leak $\ddagger$ & \\
\hline Cognitive changes & Thyroid (TSH, T4) & Dotatate & DI or SIADH & \\
\hline Altered mood/depression & Gonadal (LH, FSH, T, E) & Functional MRI & & \\
\hline Psychosis & Prolactin & & & \\
\hline Hirsutism & $\mathrm{GH}$ & & & \\
\hline Bruising/thin skin & DST, low/high dose & & & \\
\hline Osteopenia/pathologic fractures & IPSS & & & \\
\hline \multicolumn{5}{|l|}{ Fatigue } \\
\hline \multicolumn{5}{|l|}{ Acne } \\
\hline \multicolumn{5}{|l|}{ Fungal infections, UTIs } \\
\hline \multicolumn{5}{|l|}{ Proximal muscle weakness } \\
\hline \multicolumn{5}{|l|}{ Myopathy } \\
\hline \multicolumn{5}{|l|}{ "Buffalo hump" } \\
\hline \multicolumn{5}{|l|}{ Supraclavicular fat pads } \\
\hline \multicolumn{5}{|l|}{ Hair loss/balding } \\
\hline \multicolumn{5}{|l|}{ Peripheral edema } \\
\hline \multicolumn{5}{|l|}{ Pigmentation changes $\S$} \\
\hline \multicolumn{5}{|l|}{ Visual blurring } \\
\hline \multicolumn{5}{|l|}{ Poor wound healing } \\
\hline \multicolumn{5}{|l|}{ Decreased libido } \\
\hline \multicolumn{5}{|l|}{ Abdominal (and other) striae } \\
\hline \multicolumn{5}{|l|}{ Bleeding/clotting issues } \\
\hline Family history (e.g., MEN1) & & & & \\
\hline
\end{tabular}

$\mathrm{Abd}=$ abdomen; $\mathrm{ACTH}=$ adrenocorticotropic hormone; $\mathrm{CS}$ ext = cavernous sinus extension; $\mathrm{DHEAS}=$ dehydroepiandrosterone sulfate; $\mathrm{DI}=$ diabetes insipidus; $\mathrm{DST}=$ dexamethasone suppression test; $\mathrm{E}$ = estradiol; $\mathrm{FSH}$ = follicle-stimulating hormone; $\mathrm{GH}=$ growth hormone; IHC/TF = immunohistochemistry/transcription factors; IPSS = inferior petrosal sinus sampling; $\mathrm{LH}=$ leutenizing hormone; $\mathrm{LNSC}=$ late-night salivary cortisol; MEN1 = multiple endocrine neoplasia type 1; SIADH = syndrome of inappropriate antidiuretic hormone secretion; $\mathrm{T}$ = testosterone; $\mathrm{TSH}=$ thyroid-stimulating hormone; UFC = urinary free cortisol; UTI = urinary tract infection.

*Estimates cavernous sinus invasion.

†Cell proliferation marker.

$\ddagger$ Intraoperative or postoperative.

$\S$ Knuckles and elbows.

ing disease that would play important roles in machine learning outcome assessment and prediction, along with $11+$ potentially important laboratory tests and $11+$ imaging procedures, as well as operative findings and histopathological analysis results. We hope the day will soon come when these factors can be part of a comprehensive prospective data set that will be investigated by using the principles of machine learning, thereby uncovering solutions to the confounding mysteries of Cushing disease and its optimal management.

https://thejns.org/doi/abs/10.3171/2020.3.FOCUS20213

\section{References}

1. Katznelson L: The cognitive, psychological, and emotional presentation of Cushing's disease, in Laws ER Jr (ed): Cush- ing's Disease: An Often Misdiagnosed and Not So Rare Disorder. Cambridge, MA: Academic Press Elsevier, 2017

2. Langenecker SA, Weisenbach SL, Giordani B, Briceño EM, Breting LMG, Schallmo MP, et al: Impact of chronic hypercortisolemia on affective processing. Neuropharmacology 62:217-225, 2012

3. Laws ER Jr (ed): Cushing's Disease: An Often Misdiagnosed and Not So Rare Disorder. Cambridge, MA: Academic Press Elsevier, 2017

4. Laws ER Jr, Jane JA Jr: Surgical treatment of Cushing's disease, in Laws ER Jr (ed): Cushing's Disease: An Often Misdiagnosed and Not So Rare Disorder. Cambridge, MA: Academic Press Elsevier, 2017

5. Nieman L: Making the diagnosis: laboratory testing and imaging studies, in Laws ER Jr (ed): Cushing's Disease: An Often Misdiagnosed and Not So Rare Disorder. Cambridge, MA: Academic Press Elsevier, 2017 
6. Oldfield EH, Doppman JL, Nieman LK, Chrousos GP, Miller DL, Katz DA, et al: Petrosal sinus sampling with and without corticotropin-releasing hormone for the differential diagnosis of Cushing's syndrome. N Engl J Med 325:897-905, 1991

7. Pivonello R, De Leo M, Cozzolino A, Colao A: The treatment of Cushing's disease. Endocr Rev 36:385-486, 2015

8. Pouratian N, Prevedello DM, Jagannathan J, Lopes MB, Vance ML, Laws ER Jr: Outcomes and management of patients with Cushing's disease without pathological confirmation of tumor resection after transsphenoidal surgery. J Clin Endocrin Metab 92:3383-3388, 2007

9. Reitmeyer M, Vance ML, Laws ER Jr: The neurosurgical management of Cushing's disease. Mol Cell Endocrinol 197:73-79, 2002

10. Starkman MN, Giordani B, Berent S, Schork A, Schteingart DE: Elevated cortisol levels in Cushing's disease are associated with cognitive decrements. Psychosom Med 63:985993, 2001

11. Vance ML: Physical presentation of Cushing's syndrome: typical and atypical presentations, in Laws ER Jr (ed): Cushing's Disease: An Often Misdiagnosed and Not So Rare Disorder. Cambridge, MA: Academic Press Elsevier, 2017
12. Zoli M, Staartjes VE, Guaraldi F, Friso F, Rustici A, Asioli $\mathrm{S}$, et al: Machine learning-based prediction of outcomes of the endoscopic endonasal approach in Cushing disease: is the future coming? Neurosurg Focus 48(6):E5, 2020

\section{Disclosures}

The authors report no conflict of interest concerning the materials or methods used in this study or the findings specified in this paper.

\section{Correspondence}

Edward R. Laws Jr.: elaws@bwh.harvard.edu.

INCLUDE WHEN CITING

DOI: 10.3171/2020.3.FOCUS20213. 